\title{
Electric Energy Generation in Autonomous Energy Supply Module Having Rotary Expansion Engine
}

\author{
Andrei Khitrov \\ Electric drive and automation systems \\ department \\ Pskov State University \\ Pskov, the Russian Federation \\ khitrov.aa@gmail.com \\ Yulia Domracheva \\ Electric drive and automation systems \\ department \\ Pskov State University \\ Pskov, the Russian Federation \\ juli-politeh@yandex.ru
}

\author{
Alexander Khitrov \\ Electric drive and automation systems \\ department \\ Pskov State University \\ Pskov, the Russian Federation \\ khitrov-pscov@mail.ru \\ Dmitriy Fedorov \\ Electric drive and automation systems \\ department \\ Pskov State University \\ Pskov, the Russian Federation \\ dmitriy-fedorov-2012@mail.ru
}

\author{
Alexander Ilyin \\ Electric drive and automation systems \\ department \\ Pskov State University \\ Pskov, the Russian Federation \\ al.ilyin@yandex.ru
}

\begin{abstract}
The development of autonomous energy supply systems is among the priority ways of scientific and technological growth in the Russian Federation. The autonomous energy supply module providing the consumer with heat, electric power, hot and cold water can contain the different variants of the electric power subsystem. This paper considers three different variants of building the electric power subsystem for the rotary expansion engine used as a driving machine whereas the permanent magnet synchronous machine is used as a generator. Also the designed structure of $30 \mathrm{~kW}$ electric power supply subsystem is regarded.
\end{abstract}

Keywords-autonomous energy supply module, permanent magnet machines, power converters, variable speed system.

\section{INTRODUCTION}

The priority area of scientific and technological growth in the Russian Federation includes the transition to environmentally clean and resource-saving energy sector, forming new power sources and ways of storing and transporting energy [1]. As a part of that, creating autonomous energy supply plants is an actual task. This problem is particularly urgent in regions having no centralized energy supply: no heat, electricity, cold and hot water (For example, in the northern regions where the extending of the centralized power supply lines is not costeffective [2]). The autonomous energy supply module allows to solve the problems of providing consumers with necessary energy resources [3]. The autonomous energy supply module can be located in the immediate area surrounding consumers, which allows to reduce losses associated with the transportation of electric and thermal energy.

The autonomous energy supply module contains steam generator (steam boiler) having the required power and working on natural gas and (or) other types of fuel. Also the module includes the low-speed rotary expansion engine of a new type, the electric generator having electric energy converting system (which meets the requirements of the state standard [4]) and other units that provide the consumer with heat, hot and cold water.

The low-speed rotary expansion engine is used as a steam engine for driving the shaft of the electric generator. The engine of this type provides the smooth rotation of the output shaft with almost constant output torque depending on the temperature and the pressure of the working fluid of the steam generator [5].

In autonomous electric power plants having low-speed engine (up to $750 \mathrm{rpm}$ ) it is difficult to design a generating system based on the industrial synchronous generator (SG) having electromagnetic excitation, without using in such a system the electric or the mechanical multiplication. Maintaining the shaft speed in the range of fluctuations no more than $10 \%$ in synchronous generators is carried out by automatic excitation controllers. At rated speeds of 1500 or $3000 \mathrm{rpm}$ such a problem is not so acute and is easier to solve. But in all cases an electric energy generating system is not operational if the speed significantly deviates: both because of the changes in technological process (variation of the heat carrier parameters) or because of the need to control electric energy consumption in order to save the fuel.

The choice of the electric machine for the autonomous power plant is presented by the authors in [6]. It is shown that the application of the permanent magnet synchronous machine (PMSM) is perspective for reducing mass and dimensional characteristics of the power plant.

This paper considers the technical solutions for creating the electric power subsystem of the autonomous energy supply module whereas the PMSM is used as a starter-generator. 


\section{ELECTRIC POWER SUBSYSTEM CONCEPTS}

Autonomous electric power plants continue to be evolved and improved. Various autonomous power supply systems are being advanced by their composition and by their power, and their control systems are being improved. Such systems containing electric generators often produce electric energy working at the variable speed of the generator shaft.

They must convert the alternating voltage having the variable frequency to the voltage having the quality indicators for the general purpose industrial systems [4].

One of the tasks for the autonomous energy supply module is providing the consumers with three-phase voltage having constant frequency whereas the speed of the rotary expansion engine is variable. The real task is developing the autonomous electric power plant having the power up to $30 \mathrm{~kW}$ as a subsystem of the energy supply module with the rotary expansion engine having variable shaft speed from 300 to $750 \mathrm{rpm}$. The electric power subsystem must be able to control the output power to provide the effective operating modes.

The analysis of the currently existing autonomous electric power systems allows to conclude that constructing the electric subsystem of the autonomous energy supply module can be based on three concepts.

Concept I.

The first basic concept is using the SG having electromagnetic excitation, with the automatic excitation controller and the standard frequency converter (Fig. 1). Such concept is applied in diesel generator sets [7].

In the systems presented in Fig. 1 the output parameters meet the requirements of the state standard [4] generally if the speed fluctuates into the range of $10-15 \%(0.85-1.1$ of $\left.\mathrm{n}_{\mathrm{IN}}(\mathrm{rpm})\right)$.

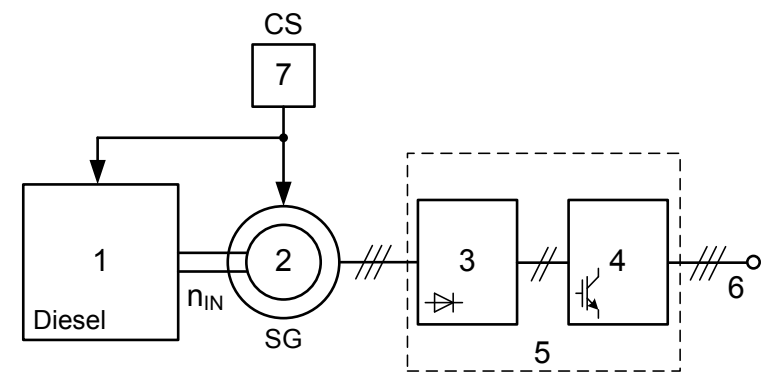

Fig. 1. Diesel generator set

Fig. 1 shows the following units: 1 - diesel engine; 2 - synchronous generator (SG); 3 - rectifier; 4 - voltage inverter; 5 - frequency converter; 6 - electric power system outputs; 7 - control system (automatic excitation controller)

In the case of the autonomous energy supply module being designed the speed could not be lower than $650 \mathrm{rpm}$. Since the SG at the low electric load is forced to work having constantly higher speed, it results in the higher fuel consumption. Electric power quality depends on the voltage inverter applied and the supplementary filters and compensating devices completing the power plant. If the voltage at the generator output is reduced lower than the acceptable level, the standard frequency converter switches off its outputs due to the error of losing the input voltage. After the outputs were blocked operating can be continued only if the voltage is increased to the level required.

The problem is also complicated with the fact that electrical corporations and firms mainly produce SG having the rated speed of 1500 and $3000 \mathrm{rpm}$. Therefore there is a need for the mechanical transmission (reduction gear, chain or belt drive, etc) between the shaft of the SG and the shaft of the driving engine (e.g. the diesel engine in Fig.1) for keeping the acceptable voltage level at the input of the rectifier at the lower speeds ( $<750 \mathrm{rpm})$.

\section{Concept II.}

The second basic concept is using the power stepup transformer (voltage multiplicator) at the output of the electric generator. Ideally it should be the regulating booster transformer having the possibility of boosting the voltage if the speed is below the acceptable level.

Applying such concept essentially increases mass and dimensional characteristics of the autonomous energy supply module (e.g. a standard transformer of the TC type having a power of $30 \mathrm{kVA}$ weighs more than $250 \mathrm{~kg}$ and has a specific power less than $0.2 \mathrm{kVA} / \mathrm{kg}$ ).

The structure of converting the mechanical energy from the engine shaft in this case is shown in Fig. 2. The stator windings of the SG are connected according to $\Delta$-connection or Y-connection.

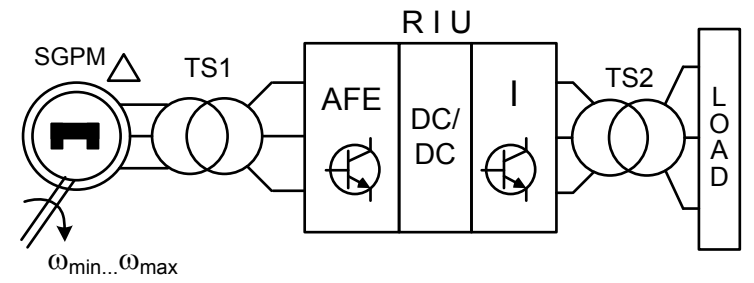

Fig. 2. The power system structure containing the step-up transformer and rectifier-inverter unit

Fig. 2 shows the following units: TS1 - step-up transformer; RIU - rectifier-inverter unit that can include the uncontrolled or the controlled rectifier (AFE), boost or buck converters of the DC voltage (DC/DC) and the output voltage inverter (I); TS2 - output isolating transformer.

\section{Concept III.}

The third basic concept is using the SG or SGPM (synchronous generator with permanent magnets) and modular electronic power converters as part of the RIU without the mechanical or electric multiplicators (Fig. 3). The units shown in Fig. 3 have the same designations as in Fig. 2; TS - output isolating transformer. This technical solution, in spite of its higher cost, has the best mass and dimensional characteristics and is promising for the autonomous electric power plants having variable speed of a driving engine. Moreover, where necessary, the SGPM (PMSM) can be used for the starter mode of the steam generator or of the wind power plant with a vertical axis of rotation (Darrieus or Savonius wind turbine type). 


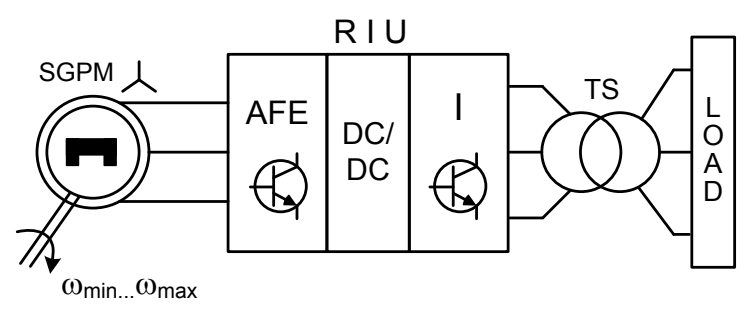

Fig. 3. The basic concept for the autonomous energy supply module without the mechanical or electric multiplicator

At the first start the power plant is in the starter mode for spinning and bringing to the required aerodynamic performance. After that the power plant should be driven into the generator mode. Such wind power plants have various advantages over the wind plants with a horizontal axis of rotation: operating with the wind of any direction, no need in wind orientation system, reduced mass and dimensional characteristics of the engine. Such systems can be closely established near the autonomous energy supply module container and serve as an auxiliary power supply system for the module (including the function of recharging the accumulator batteries contained in the autonomous energy supply module).

\section{III. $\quad 30 \mathrm{KW}$ SySTEM DESIGN}

Fig. 4 shows the designed structure and the composition for the $30 \mathrm{~kW}$ electric subsystem of the autonomous energy supply module.

The module contains the following basic units and systems:

1. Accumulator batteries unit $(\mathrm{AB})$ consisting of 5 batteries (lead-acid helium sealed) and charger 1 controlling the charging process (individually for each battery) and limiting the charging current.

2. Power converters (controlled units) for providing the auxiliaries of the autonomous energy supply module and monitoring the output power changes and fluctuations.

- UZ1 - inverter for controlling the start of the REE - rotary expansion engine (an additional option if required). It is implemented on the base of the standard $3 \mathrm{~kW}$ frequency converter having the ability to be connected to the $48 \mathrm{~V}$ DC-bus (e.g. Unidrive SP 1402) or using DC/AC converter $48 \mathrm{~V} \mathrm{DC} / 3 \times 380 \mathrm{~V}$ AC of $3 \mathrm{~kW}$ power. The module can be equipped with the supercapacitor (e.g. LSUM048R6C) and the charger 2.

Instead of using UZ1 the soft starter device can be applied (e.g. MCT-331H of SPC Bitek, The Russian Federation [8]). In this case it is connected to output of the UZ2 inverter.

- UZ2 - inverter for creating the local three-phase $380 \mathrm{~V}$ AC network. 4kVA inverter UZ2 is supplied from input DC voltage 48-60V.

- UZ3 - electric network inverter having the input DC voltage $+24 \mathrm{~V}$ and the output single-phase AC voltage $220 \mathrm{~V}, 50 \mathrm{~Hz}$. The AC/DC converters forming the stabilized voltages of the needed values for supplying low power electric devices and sensors are connected to the output of UZ3.

- UZ4 - rectifier-inverter unit (RIU) with output isolating transformer TS2 of $30 \mathrm{kVA}$ power. The composition of the RIU is determined by the type of an electric generator of the autonomous power plant.

3. Generator unit on the base of SG or SGPM (e.g. SGPM of the LSRPM 250SE type, Leroy Somer [9]) having the power of $31 \mathrm{~kW}$, the speed of 710 rpm and the embedded speed sensor (encoder EN) and air cooling system.

4. Autonomous power energy module control system (APEM CS) with sensors and auxiliary units. The control system is intended for controlling the operating modes of the power energy module.

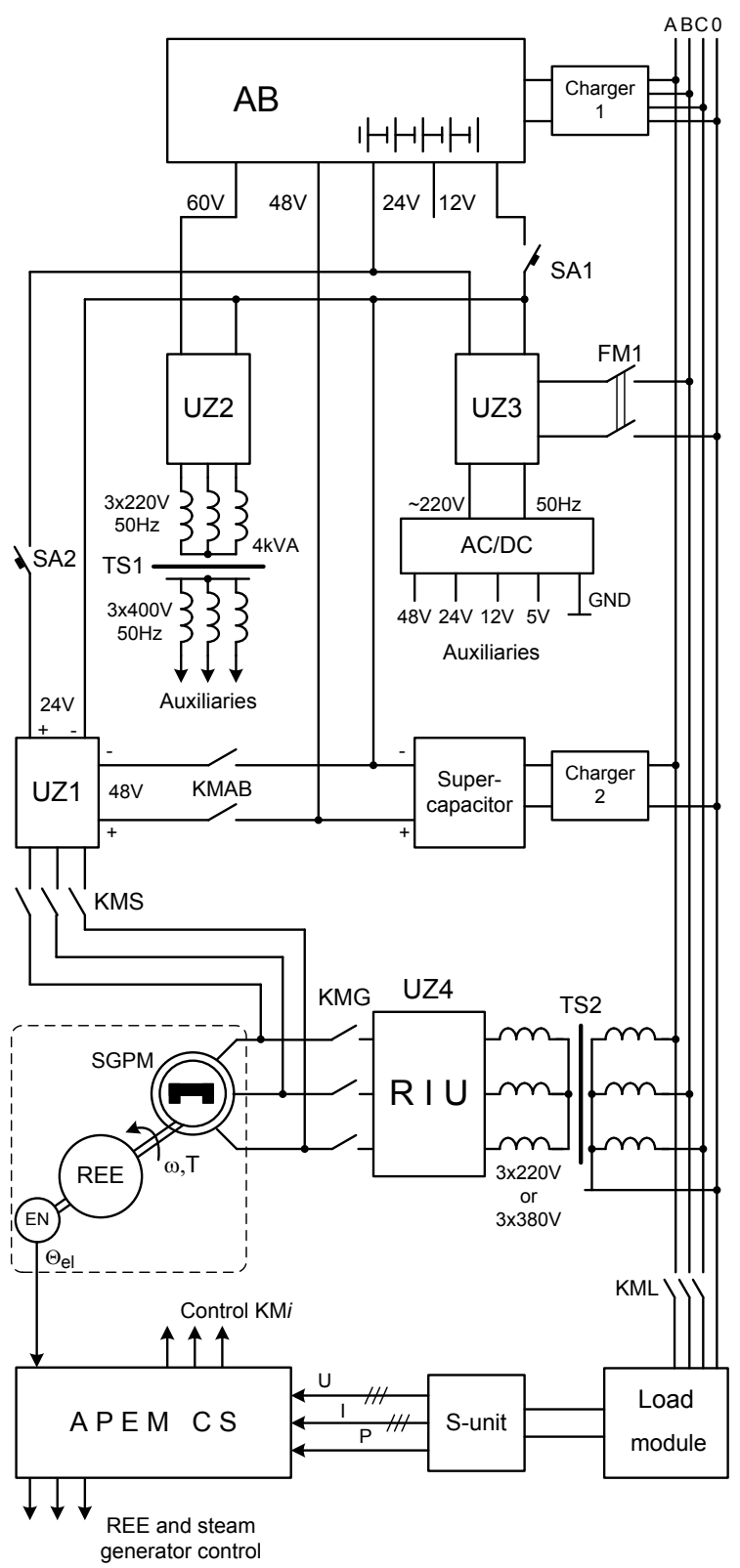

Fig. 4. $30 \mathrm{~kW}$ autonomous energy supply module electric subsystem

The signals of the output variables states (output AC network variables: currents, voltages, power consumption) from the sensors unit (S-unit) and the generator shaft speed from the generator unit come to the input of the 
APEM CS. The output signals of the APEM CS are the signals of regulating the switching equipment and connecting the load module for balancing the autonomous electric network load. Also the output variables of the APEM CS are the control signals for the steam generator for providing the effective and energy-saving operating modes.

5. Switching and protection equipment.

- SA1 - switch for connecting the AB unit (DC contactor $100 \mathrm{~V}, 60 \mathrm{~A})$.

- SA2 - switch (circuit breaker or contactor 30V, 1A) for supplying the auxiliaries of the UZ1 inverter.

- FM1 - single-phase circuit breaker or AC contactor. It is being connected after switching to the autonomous supply of the auxiliaries from the own network. FM1 prevents the discharge of the $\mathrm{AB}$ unit.

- $\mathrm{KMAB}$ - DC contactor for connecting 48V DC voltage from the output of the $\mathrm{AB}$ unit or the supercapacitor to the input of the UZ1 inverter.

- $\mathrm{KMS}-$ switch $(3 \times 380 \mathrm{~V}$ AC contactor, $10 \mathrm{~A})$ for connecting the stator winding of the SGPM to three-phase voltage for the idle start of the REE. Then the engine reaches the nominal conditions at the «light» operating mode till the speed is 600$700 \mathrm{rpm}$.

- $\mathrm{KMG}-$ switch $(3 \times 380 \mathrm{~V}$ AC contactor, 50A) for connecting the output of SGPM to the RIU after the starting procedure was completed and the KMS switch was switched off.

- $\mathrm{KML}$ - AC contactor for connecting the load module.

Fig. 5 shows the module structure of the power circuit as a technical solution for the RIU. Such solution may be effective for the autonomous energy supply module [10] $-[12]$ :

1. Three-step principle of converting the electric energy from the SGPM. The structure of the RIU based on this principle includes the uncontrolled or the controlled (active) rectifier - module 1, the boost DC/DC converter operating at the high frequency (more than $10 \mathrm{kHz}$ ) - module 2, the inverter of the required power having the input control of the $\mathrm{DC}$ voltage (450-600V) and the sensorless vector control mode - module 3 . The DC voltage multiplication factor of the module 2 is in the range from 2 to 3,5 . The output of the RIU is connected to filter F or an isolating transformer (which is more preferable). The power circuit of the rectifier, the DC/DC converter and the inverter can be manufactured as separate complete devices. There can be two separate control systems for the DC/DC converter and the inverter or single combined control system for two modules.

2. The autonomous energy supply module of this type has optimal mass and dimensional characteristics for the output power given, and these characteristics mostly depend on the applied SGPM and the implemented control principle of the RIU [6]. The module can provide the power control without electric power sensors if the calibration curves of the power plant (the steam generator and the rotary expansion engine at the rated shaft speed) are known in advance.

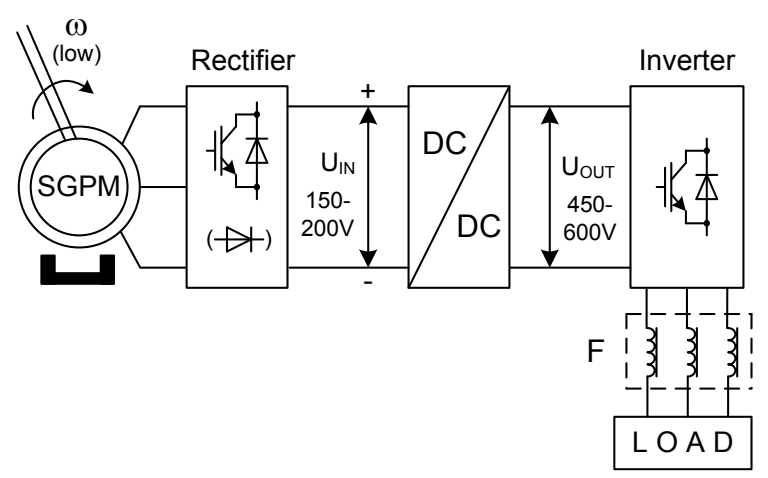

Fig. 5. Module structure of the power circuit

The ready-made technical solutions analysis made by the authors allows to note that currently there are no high power DC/DC converters manufactured by the industrial companies for integrating into the systems with frequency converters having an option of connecting to the DC-bus.

There are no various options for purchasing the inverters with input DC voltage and output three-phase AC voltage that are not complete standard frequency converters in the market of electric products in the Russian Federation. Such technical decisions are available at the markets for the solar power systems. E.g. the inverter Omega $11 \mathrm{~kW}$ (solar inverter for the power water pump [13]) of MasterPower (Spain) having the input DC voltage range from $250 \mathrm{~V}$ to $800 \mathrm{~V}$ and the output three-phase AC voltage of $380 \mathrm{~V}$.

Scientific articles and patents [12], [14] confirm the relevance of the solution of the technical problem in designing autonomous electric power plants of various power and of different purposes with variable speed of a driving engine and controlling output electric power for efficiency increasing.

\section{CONCLUSION}

The designed electric power subsystem of $30 \mathrm{~kW}$ power for the autonomous energy supply module is given in this article.

The synchronous generator with permanent magnets (SGPM) is recommended to be applied as an electric generator within the autonomous energy supply module.

The structures including SGPM without using electric or mechanical multiplicators have the limited possibilities of regulating the output voltages. It requires designing the special type of the rectifier-inverter unit (RIU) of the module type including the rectifier (controlled or uncontrolled) module, the boost DC/DC converter and the inverter having an option of connecting to the DC-bus.

\section{REFERENCES}

[1] Decree of the President of the Russian Federation of 01.12.2016, No. 642. About the Strategy for the Scientific and Technological Development of the Russian Federation. 25 p. (In Russian).

[2] Mikhalap S.V., Khutornoy A.N. Alternative power supply for northern rural settlements. Promyshlennaya energetika. [Industrial Energy Magazine]. №10, 2018. pp. 46-52. (In Russian).

[3] Khitrov A.I., Khitrov A.A. Electric machine switch system as part 
of the cogeneration power plant. Elektroprivody peremennogo toka: Trudy mezhdunarodnoy shestnadtsatoy nauchnotekhnicheskoy konferentsii. [Proc. 16-th Int. Conf. «AC Electric Drives»]. Yekaterinburg, Ural Federal University named after the first President of Russia B. N. Yeltsin. 2015. pp.218-219. (In Russian).

[4] State Standard 32144-2013. Electric Energy. Electromagnetic compatibility. Standards of quality of electric energy in generalpurpose power supply systems. (In Russian).

[5] Lukyanov Y.N., Perminov A.L. and oth. Rotornaya rasshiritelnaya mashina. [Rotary expansion machine]. Patent RF № 2619391. 15.05.2017. (In Russian).

[6] Khitrov A.I., Khitrov A.A. Justification of electric machine choice for autonomous electric low-power supply system working with low-speed variable speed engine. Vestnik Pskovskogo gosudarstvennogo universiteta. Seriya «Tekhnicheskie nauki». [PskovSU journal. «Technical science» series]. Vol. 7, 2018. pp. 57-71. (In Russian).

[7] Khvatov O.S., Darenkov A.B., Tarasov I.M. Diesel generator power station with variable shaft speed. Vestnik IGEU. [Ivanovo State Energetic University Journal]. Vol. 2. 2010. (In Russian). pp. 53-56. (In Russian).

[8] Scientific Production Company «Bitek». Soft starters / electronic starters. [Online]. Available: http://bitek-e.ru/softstart.htm [Accessed: Febr. 19, 2019].
[9] Permanent magnet synchronous motor 3 to $350 \mathrm{~kW}-1500$ to 5500 rpm. [Online]. Available: http://acim.nidec.com/ motors/leroysomer/products/permanent-magnet-synchronous-motors/ 1srpmdyneo [Accessed: Febr. 19, 2019].

[10] Khitrov A.I., Khitrov A.A., Veselkov E.L. Three-phase inverter for autonomous electric power supply low-power systems Vestnik Pskovskogo gosudarstvennogo universiteta. Seriya «Tekhnicheskie nauki». [PskovSU journal. «Technical science» series]. Vol 2, 2015. pp.70-79. (In Russian).

[11] Khitrov A.A., Khitrov A.I. Investigations of Electric Power Quality in Autonomous Low Power Plant. Environment. Technology. Resourses. Proceeding of the 11th International Scientific and Practical Conference. Rezekne, Latvia. June 15-17, 2017. Volume Ш. pp.136-139.

[12]Plokhov I.V., Khitrov A.A., Khitrov A.I. Starter-generatornaya ustanovka dlya avtonomnoy sistemy elektrosnabzheniya na baze rotorno-lopastnogo dvigatelya s vneshnim podvodom teploty. [Starter-generator set for autonomous power supply system for external combustion rotary-vane engine]. Patent RF №144521. 27.08.2014. (In Russian).

[13] Omega. Solar Inverter for Water Pump. User manual. [Online]. Available: http://www.masterbattery.es/manuales/ Omega Water_Pump.pdf [Accessed: Febr. 21, 2019].

[14]Darenkov A.B. Avtonomnaya elektrostantsiya peremennogo toka. [Isolated alternating current electric power station]. Patent RF № 2666903. 13.09.2018. (In Russian). 